\title{
АНАЛИЗ ОСНОВНЫХ ПОКАЗАТЕЛЕЙ РАЗВИТИЯ ЭКОНОМИКИ ИСЛАМСКОЙ РЕСПУБЛИКИ ИРАН *
}

\section{(C) 2020 Никифорова Наталья Александровна}

кандидат экономических наук, доцент, профессор Департамента бизнес-аналитики Финансовый университет при правительстве Российской Федерации, Россия, Москва E-mail: nanikiforova@fa.ru

(c) 2020 Боровицкая М.В.

кандидат экономических наук, доцент Департамента бизнес-аналитики Финансовый университет при Правительстве Российской Федерации, Россия, Москва E-mail: MVBorovitskaya@fa.ru

(c) 2020 Шнайдер В.В.

кандидат экономических наук, доцент департамента магистратуры (бизнес-программ) Тольяттинский государственный университет, Россия, Тольятти

E-mail: gerutti1881@mail.ru

Целью статьи является анализ основных показателей развития экономики Исламской Республикой Иран (ИРИ). В статье приведена характеристика динамики и перспектив макроэкономических параметров развития различных секторов. Дан развернутый анализ деловой активности и проблем экономического состояния Ирана.

Ключевые слова: динамика валового внутреннего продукта, темпы создания рабочих мест, уровень безработищы, анализ показателей населения и по труду, анализ деловой среды.

Структура иранской экономики весьма диверсифицирована. Несмотря на то, что Иран делит с Россией первенство по суммарным запасам углеводородов, доля нефтехимической промышленности в структуре ВВП порядка $23 \%$. Большую часть занимают услуги - $47 \%$, на долю промышленности и горной добычи приходится около $20 \%$, а сельское хозяйство приносит $10 \%$ в ВВП.

Экономика Ирана характеризуется углеводородным сектором, сельским хозяйством и сферой услуг, а также заметным государственным присутствием в сфере производства и финансовых услуг. Иран занимает второе место в мире по запасам природного газа и четвертое по доказанным запасам сырой нефти. Экономическая активность и государственные доходы по-прежнему в значительной степени зависят от нефтяных доходов и поэтому остаются нестабильными.

Власти Ирана приняли всеобъемлющую стратегию, охватывающую рыночные реформы, отраженную в 20-летнем правительственном концептуальном документе и шестом пятилетнем плане развития на период 2016-2021 годов.

Шестой пятилетний план развития состоит из трех этапов, а именно: развитие устойчивой экономики, прогресс в науке и технике и содействие культурному развитию. На экономическом фронте план развития предусматривает ежегодные темпы экономического роста в 8 процентов и реформы государственных предприятий, финансового и банковского сектора, а также распределение и управление нефтяными доходами среди основных приоритетов правительства в течение пяти лет.

По оценкам, валовой внутренний продукт (ВВП) Ирана в 2018 году составил 1610,7 млрд. долларов США, а население - 80,6 млн. человек. Сравнение валового внутреннего продукта России и ИРИ в 1980-2018 годах показано на рисунке 1.

Рост реального ВВП замедлился до 4 процентов в 2018/19 гг., поскольку добыча нефти стабилизируется в соответствии с ограничением Ирана в ОПЕК и, по прогнозам, в среднесрочной

\footnotetext{
* Статья подготовлена по результатам исследования в рамках НИР «Расширение взаимовыгодного торговоэкономического сотрудничества между Россией и Ираном», выполненного за счет бюджетных средств по государственному заданию Финуниверситета.
} 


\section{Валовой внутренний продукт стран в 1980- 2018 годах}

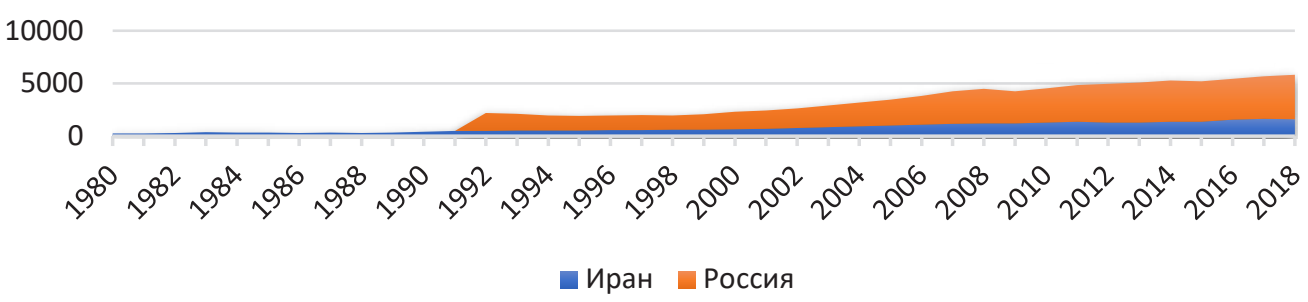

Рисунок 1. Динамика валового внутреннего продукта России и ИРИ в 1980-2018 годах [1].

перспективе составит 4,5 процента.

По данным экспертов ожидается, что текущий бюджет останется профицитным, поскольку увеличение экспорта газа позволяют постепенно наращивать резервы международных резервов.

Ожидается так же, что сохраняющаяся неопределенность будет сдерживать прямые зарубежные инвестиции и препятствовать дальнейшему расширению отношений с банками-корреспондентами.

Темпы создания рабочих мест в Иране отстают, что необходимо для поглощения большого числа новых участников, присоединяющихся к рынку труда, что означает, что безработица может остаться выше 11 процентов (рисунок 2).

Уровень безработицы среди мужчин и женщин, составляющий 10,2 и 19,7 процента соответственно, свидетельствует о сохранении гендерного разрыва на рынке труда. Уровень безработицы среди молодежи (15-24 года), составивший 28,3 процента в июне 2018 года, остается высоким по сравнению с более ранними периодами и в среднем по региону.
Средний возраст населения: всего: 31,7 года; мужчины: 31,5 лет женщины: 32 года (2020 год) Темпы роста населения 1,1\% (2020 год).

В таблице 1 отражены данные по труду и населению Исламской Республики Иран.

Особенностями показателей населения и по труду в ИРИ является тот факт, что трудоспособное население, в основном, молодого возраста и - это, в основном мужчины. В Иране низкий уровень заработной платы. Это дает определенные выгоды для работы в этом регионе мира российским компаниям в рамках двустороннего сотрудничества.

Основные макроэкономические показатели развития ИРИ показаны в таблице 2 .

Подавляющее большинство роста ВВП пришлось на ненефтяные сектора, из которых более половины можно отнести на рост услуг на 4,4 процента. Нефтяной сектор, сельское хозяйство и сфера услуг в настоящее время вернулись к уровням активности, которые были до введения санкций в 2012-2013 гг. Но в последние два года не наблюдалось сильного отскока в ключевых секторах, таких как строительство и торговля,

\section{ИРАН}

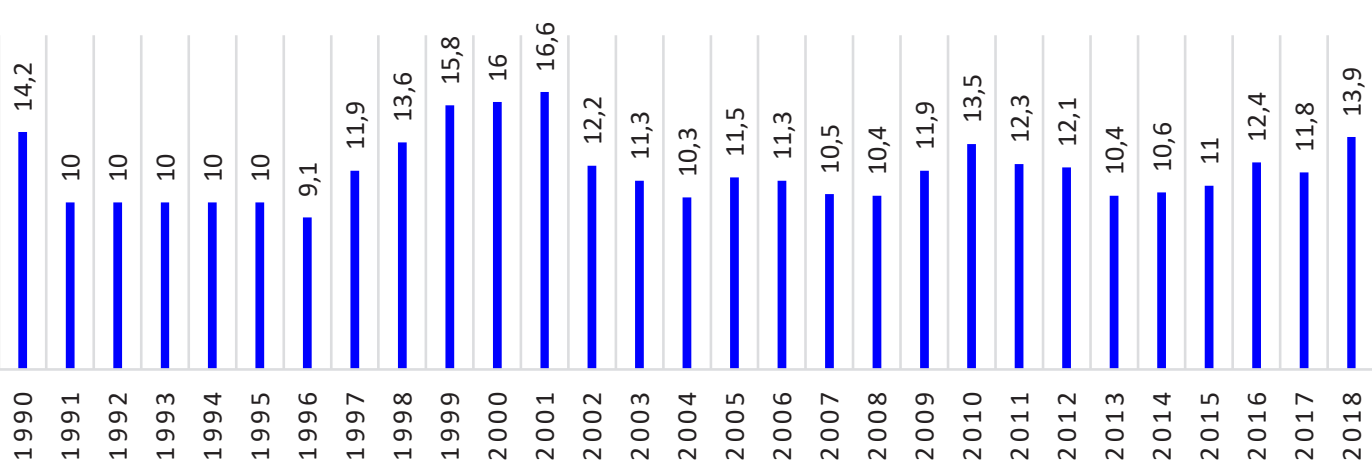

Рисунок 2. Уровень безработицы ИРИ в 1990-2018 гг.,\% от общей численности трудоспособного населения [1]. 
Таблица 1. Исламская Республика Иран: данные по труду и населению, 2015/16-2022/23 [2]

\begin{tabular}{|c|c|c|c|c|c|c|c|c|}
\hline \multirow[t]{2}{*}{ Наименование } & \multicolumn{8}{|c|}{ (Миллионы людей, если не указано иное) } \\
\hline & $2015 / 16$ & $2016 / 17$ & $2017 / 18$ & $2018 / 19$ & $2019 / 20$ & $2020 / 21$ & $2021 / 22$ & $2022 / 23$ \\
\hline Население & 79,5 & 80,5 & 81,4 & 82,4 & 83,3 & 84,1 & 85,0 & 85,8 \\
\hline $\begin{array}{l}\text { Население трудоспособного } \\
\text { возраста }\end{array}$ & 64,6 & 65,4 & 65,9 & 66,5 & 67,0 & 67,5 & 68,1 & 68,8 \\
\hline Рабочая сила & 24,7 & 25,8 & 26,2 & 26,5 & 26,9 & 27,3 & 27,7 & 28,1 \\
\hline Занятость & 22,0 & 22,6 & 23,1 & 23,4 & 23,8 & 24,2 & 24,6 & 25,0 \\
\hline Безработица & 2,7 & 3,2 & 3,1 & 3,1 & 3,1 & 3,1 & 3,1 & 3,2 \\
\hline \multirow[t]{2}{*}{$\begin{array}{l}\text { Номинальный ВВП на душу } \\
\text { населения (долл. США) }\end{array}$} & 4,723 & 5,027 & 5,305 & 5,086 & 4,961 & 4,732 & 4,949 & 5,202 \\
\hline & \multicolumn{8}{|c|}{ (Процент) } \\
\hline Коэффициент участия: & 38,2 & 39,4 & 39,7 & 39,9 & 40,2 & 40,4 & 40,7 & 40,9 \\
\hline - мужской & 63,2 & 64,1 & 64,9 & & & & & \\
\hline - женский & 13,3 & 14,9 & 16,5 & & & & & \\
\hline Уровень безработицы: & 11,0 & 12,4 & 11,8 & 11,7 & 11,6 & 11,4 & 11,4 & 11,2 \\
\hline - мужской & 9,3 & 10,5 & 10,1 & & & & & \\
\hline - женский & 19,4 & 20,7 & 20,4 & & & & & \\
\hline \multirow[t]{2}{*}{ - молодежь } & 26,1 & 29,1 & 28,1 & & & & & \\
\hline & \multicolumn{8}{|c|}{ (Годовое процентное изменение) } \\
\hline $\begin{array}{l}\text { Номинальный ВВП на душу } \\
\text { населения }\end{array}$ & $-2,4$ & 12,9 & 14,7 & 20,0 & 14,4 & 13,6 & 13,8 & 13,9 \\
\hline $\begin{array}{l}\text { Реальный ВВП на душу } \\
\text { населения }\end{array}$ & $-2,8$ & 11,1 & 3,0 & 2,8 & 2,8 & 3,0 & 3,2 & 3,4 \\
\hline Население & 1,3 & 1,2 & 1,2 & 1,2 & 1,1 & 1,1 & 1,0 & 1,0 \\
\hline Рабочая сила & 3,6 & 4,5 & 1,4 & 1,4 & 1,4 & 1,4 & 1,6 & 1,6 \\
\hline Занятость & 3,1 & 2,8 & 2,1 & 1,5 & 1,6 & 1,6 & 1,6 & 1,7 \\
\hline Безработица & 7,5 & 18,0 & $-3,6$ & 0,9 & 0,2 & $-0,3$ & 1,1 & 0,2 \\
\hline \multicolumn{9}{|c|}{ Источники: власти Ирана, а также оценки и прогнозы персонала МВФ. } \\
\hline Финансовый гоп в Иране закан & & & & & & & & \\
\hline
\end{tabular}

Таблица 2. Исламская Республика Иран: отдельные макроэкономические показатели, 2015/16-2022 23 гг. [2]

\begin{tabular}{|l|c|c|c|c|c|c|c|c|c|c|}
\cline { 2 - 9 } \multicolumn{1}{l|}{} & $2015-16$ & $2016-17$ & $2017-18$ & $2018-19$ & $2019-20$ & $2020-21$ & $2021-22$ & $2022-23$ \\
\cline { 2 - 9 } \multicolumn{1}{l|}{} & \multicolumn{7}{|c|}{ (Годовое процентное изменение, если не указано иное) } \\
\cline { 2 - 9 } & \multicolumn{7}{|c|}{ Национальные счета } \\
\hline $\begin{array}{l}\text { Номинальный ВВП по } \\
\text { лионы иранских риалов) }\end{array}$ & 11,129 & 12,723 & 14,772 & 17,926 & 20,742 & 23,811 & 27,365 & 31,464 \\
\hline $\begin{array}{l}\text { Реальный ВВП по факти- } \\
\text { ческой стоимости }\end{array}$ & $-1,60$ & 12,50 & 4,30 & 4,00 & 4,00 & 4,10 & 4,20 & 4,40 \\
\hline Реальный нефтяной ВВП & 7,20 & 61,60 & 5,20 & 4,60 & 3,70 & 3,80 & 4,00 & 4,00 \\
\hline $\begin{array}{l}\text { Реальный ненефтяной } \\
\text { ВВП }\end{array}$ & $-3,10$ & 3,30 & 4,00 & 3,80 & 4,10 & 4,20 & 4,20 & 4,50 \\
\hline Инфляция ИПЦ (средняя) & 11,90 & 9,10 & 9,90 & 12,10 & 11,50 & 11,70 & 11,30 & 10,80 \\
\hline $\begin{array}{l}\text { Уровень безработицы } \\
\text { (в процентах от рабочей } \\
\text { силы) }\end{array}$ & 11,00 & 12,40 & 11,80 & 11,70 & 11,60 & 11,40 & 11,40 & 11,20 \\
\hline
\end{tabular}


Продолжение таблицы 2

\begin{tabular}{|l|c|c|c|c|c|c|c|c|c|}
\hline & \multicolumn{7}{|c|}{ (Процент от ВВП) } \\
\hline $\begin{array}{l}\text { Всего инвестиций в основ- } \\
\text { ной капитал }\end{array}$ & 23,30 & 20,90 & 20,90 & 21,50 & 22,50 & 23,60 & 24,70 & 25,70 \\
\hline государственный & 2,50 & 3,30 & 2,30 & 3,70 & 2,50 & 2,50 & 2,50 & 2,60 \\
\hline Частный & 20,80 & 17,70 & 18,60 & 17,80 & 20,00 & 21,10 & 22,20 & 23,10 \\
\hline $\begin{array}{l}\text { Валовые национальные } \\
\text { сбережения }\end{array}$ & 35,20 & 37,60 & 40,40 & 43,20 & 43,00 & 42,90 & 43,50 & 44,20 \\
\hline государственный & 0,60 & 0,20 & 0,10 & 1,10 & 0,30 & 0,30 & 0,20 & 0,10 \\
\hline Частный & 34,60 & 37,30 & 40,40 & 42,00 & 42,60 & 42,60 & 43,30 & 44,10 \\
\hline Внешний сектор & & $($ В миллиардах долларов США, если не указано иное) & \\
\hline Экспорт товаров и услуг & 74,40 & 94,40 & 109,50 & 130,30 & 127,50 & 126,10 & 129,70 & 134,00 \\
\hline Импорт товаров и услуг & $-74,00$ & $-79,50$ & $-91,50$ & $-103,30$ & $-103,70$ & $-105,40$ & $-107,50$ & $-110,00$ \\
\hline $\begin{array}{l}\text { Общий объем экспорта } \\
\text { нефти и газа }\end{array}$ & 26,90 & 49,80 & 63,70 & 78,30 & 73,60 & 69,20 & 70,30 & 72,30 \\
\hline $\begin{array}{l}\text { Экспорт сырой нефти } \\
\text { (млн. Баррелей в день) }\end{array}$ & 1,40 & 2,10 & 2,50 & 2,70 & 2,80 & 2,90 & 3,00 & 3,10 \\
\hline $\begin{array}{l}\text { Добыча сырой нефти } \\
\text { (млн. Баррелей в день) }\end{array}$ & 2,90 & 3,70 & 3,80 & 3,80 & 3,90 & 4,10 & 4,30 & 4,40 \\
\hline
\end{tabular}

ресторанное и гостиничное обслуживание, после стагнации роста в период санкций и перевеса проблем банковского сектора.

Дальнейшее улучшение деловой среды будет способствовать ускоренному развитию частного ненефтяного сектора. В большинстве исследований доступ к финансам остается основным препятствием для бизнеса, за которым следуют бюрократия и нестабильность политики. Меньше бюрократизма, современные правила, реформированная система банкротства, либерализованные цены и меньшее количество барьеров для входа могут помочь частному сектору работать на более равных условиях с государственными предприятиями.

Наиболее проблемные факторы для ведения бизнеса: нормативно-правовые акты, огра- ничивающие труд, доступ к финансированию, неэффективное управление посредством государственной бюрократии, недостаточный запас инфраструктуры, инфляция, коррупция, политическая нестабильность (рисунок 3).

Эффективная антикоррупционная структура, соответствующая международным стандартам, также укрепит подотчетность, улучшит деловой климат и поможет привлечь иностранные инвестиции [4].

Двусторонние и многосторонние торговые соглашения сокращают доступ на рынок для иранских фирм. Тарифы, применяемые к экспорту Ирана его торговыми партнерами, составили в среднем 8,9\% в 2014 г. (средний мировой показатель 2,9\%). Внутренние импортные тарифы в среднем составили 20,9\% в 2017/18 гг., а

Most Problematic Factors for Doing Business

(Lower score is better)

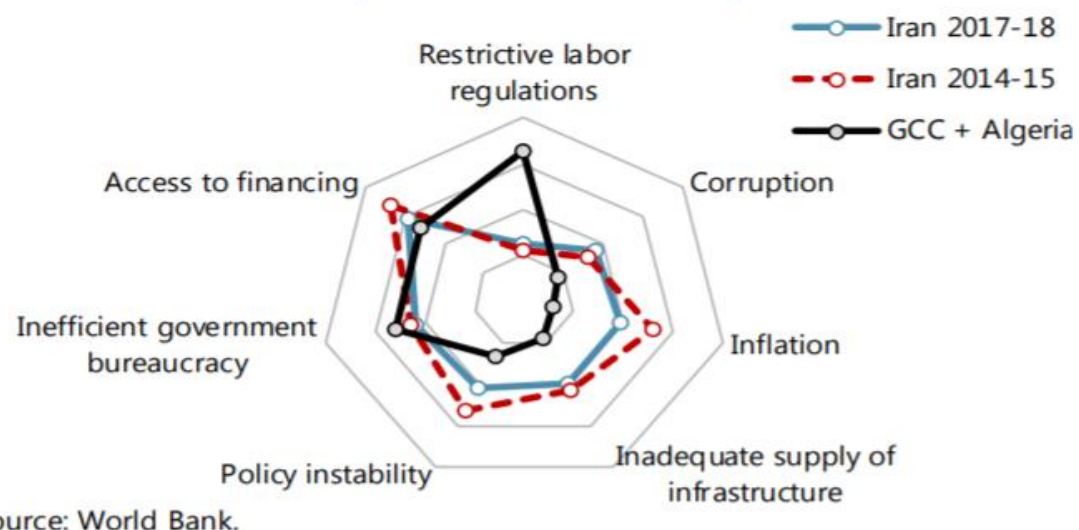

Source: World Bank.

Рисунок 3. Наиболее проблемные факторы для ведения бизнеса [3] 


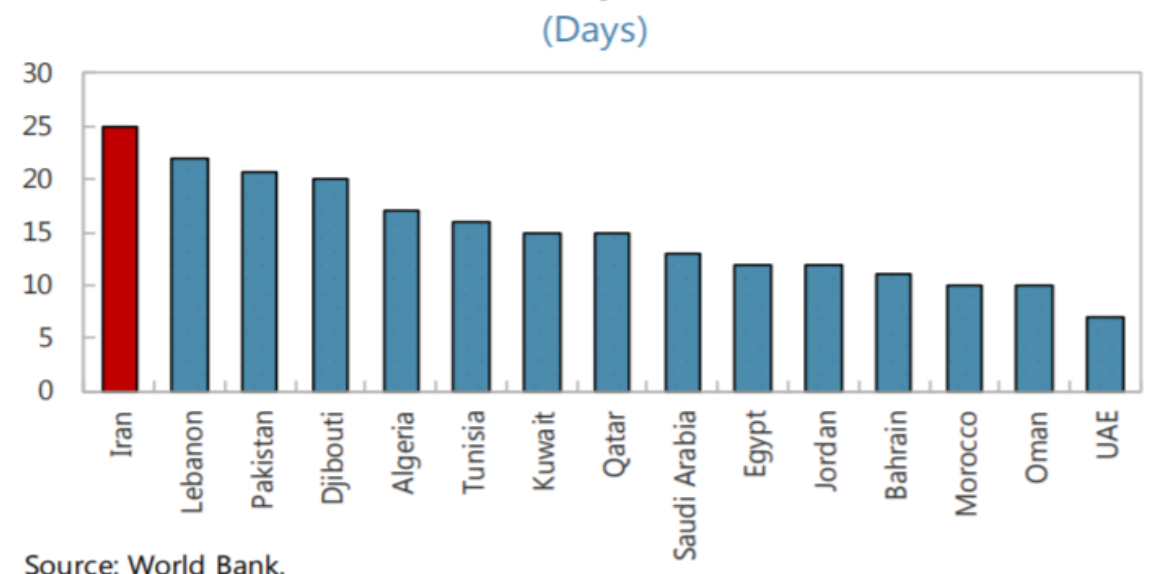

Source: World Bank.

Рисунок 4. Продолжительность экспортных операций (в днях) [3]

ограничения на торговлю услугами (четвертое место в мире) направлены на защиту неэффективных субъектов хозяйствования. Требуется 25 дней, чтобы осуществить экспорт (рисунок 4).

Экономические и социальные трудности Тегерана продолжаются в 2020 году на фоне продолжающейся кампании давления со стороны Соединенных Штатов, которые постоянно затягивают гайки, и разочарованного населения, которое, как предупреждают наблюдатели, может снова выйти на улицы. Эти трудности также осложняются распространенной во всем мире пандемией COVID-19. Многие простые иранцы сильно пострадали от экономического спада.

Кеннет Кацман, старший аналитик по Ира- ну в Исследовательской службе Конгресса, заявил The Washington Post в сентябре, что у Ирана по-прежнему есть резервы на сумму около 100 миллиардов долларов, добавив, что в нынешних условиях эта ситуация продлится для иранцев как минимум еще два года. Но специальный представитель США по Ирану Брайан Хук заявил в декабрьском (2019 г.) интервью The Wall Street Journal, что благодаря секретной информации Иран имеет доступ только к 10 процентам своих валютных резервов из-за банковских санкций и что в результате он будет бороться чтобы стабилизировать свою валюту и сдерживать инфляцию.

\section{Библиографический список}

1. http://svspb.net/danmark/vvp-stran.php

2. https://www.imf.org/en/Publications/Search?series=\&when=After\&title=Iran

3. IMF Country Report No. $18 / 93$

4. Филимонов С.В., Невежин В.П. Зависимость потребления электроэнергии в разных странах от различных факторов. // Экономика и социум. 2016. № 4-2 (23). С. 414-417. 